\title{
Stabilization of Pitch Derived Ultrafine Particles by Iodine Treatment
}

\author{
Hisashi Kajiura*, Yasuhiro Tanabe, Masaya Kodama** and Eiichi Yasuda
}

(Received April 17, 1996)

Materials and Structures Laboratory, Tokyo Institute of Technology

4259 Nagatsuta, Midori-ku, Yokohama 226, Japan

*Research Fellow of the Japan Society for the Promotion of Science

**Inorganic Composite Materials Department,

Kyushu National Industrial Research Institute

Shuku-machi, Tosu-city, Saga 841, Japan

\begin{abstract}
Ultra-fine particles (UFP) were prepared from coal tar pitch (CTP) and A240 pitch by anti-solvent procedures using quinoline and acetone as a rich and a poor solvents, respectively. The size of the obtained UFP depended upon the pitch/quinoline ratio and starting materials. The UFP with about $50 \mathrm{~nm}$ in diameter could be obtained from CTP under an appropriate condition. The UFPs were treated with iodine at $90^{\circ} \mathrm{C}$ for stabilization, followed by a carbonization process at $800^{\circ} \mathrm{C}$ for 1 hour with the heating rate of $2.5{ }^{\circ} \mathrm{C} / \mathrm{min}$ in Ar flow. A suitable iodine treatment was effective to preserve the shape of UFP after carbonization. The carbon yield of the UFP increased by the iodine treatment. Therefore, it was clarified that the UFP was able to be stabilized by the iodine treatment.
\end{abstract}

KEYWORDS : Ultra-fine particle, Anti-solvent procedure, Iodine treatment, Stabilization, Pitch.

\section{Introduction}

The fine particles have some unique characters which originate from their morphology and large specific surface area. Carbonaceous particles are expected to be excellent raw materials for high density carbon materials or column packing materials for chromatography. Some papers presented procedures in making carbonaceous particles from pitches ${ }^{1)},{ }^{2)}$. M.Kodama et al. ${ }^{3)}$ made fine carbonaceous particles with $40 \mathrm{~nm}$ in diameter, called ultra-fine particle (UFP), from coal tar based mesophase pitch having a softening point (SP) of $300^{\circ} \mathrm{C}$ by an anti-solvent procedure. This procedure utilizes the solubility difference of pitch in quinoline and in acetone. They also reported in the same paper that the UFP could be stabilized by a heat treatment at $250-350{ }^{\circ} \mathrm{C}$ in an oxidizing atmosphere.

The authors tried making UFP from pitches having the SP of about $100{ }^{\circ} \mathrm{C}$ by anti-solvent procedure employing quinoline and acetone as solvents, and to stabilize the obtained UFP at lower temperature. Since the SP of used pitches is lower than that of the pitch used by Kodama et al., it is impossible to stabilize the UFP by the heat treatment at $250-350^{\circ} \mathrm{C}$ in an oxidizing atmosphere. The authors reported in a previous paper ${ }^{4}$ that the pitch could be stabilized by iodine treatment at $90^{\circ} \mathrm{C}$. The purpose of the present study is to demonstrate the effectiveness of the iodine treatment to stabilize the UFP.

\section{Experimental Procedure}

Coal tar pitch (CTP, Nippon Steel Chemical Co.) and petroleum pitch (A240, Ashland Petroleum Co.) were selected as starting materials. The characteristics of pitches are summarized in Table 1. The fraction of acetonesoluble pitch was preliminary removed by a solvent frac- 
Table 1 The characteristics of used pitches

\begin{tabular}{lcc}
\hline & $\mathrm{CTP}$ & $\mathrm{A} 240$ \\
\cline { 2 - 3 } Softening Point & $101^{\circ} \mathrm{C}$ & $103{ }^{\circ} \mathrm{C}$ \\
Fixed Carbon & $53.3 \%$ & $50.3 \%$ \\
Acetone Insoluble & $68 \%$ & $60 \%$ \\
Quinoline Insoluble & $0.59 \%$ & $0 \%$ \\
Ash & $0.02 \%$ & $0.03 \%$ \\
Sulfur & $0.50 \%$ & $3.30 \%$ \\
\hline
\end{tabular}

tionation method. The pitch was then dissolved in quinoline by keeping at $75^{\circ} \mathrm{C}$ for 6 hours. The pitch/quinoline ratio of $0.02 \mathrm{~g} / \mathrm{ml}$ and $0.1 \mathrm{~g} / \mathrm{ml}$ were prepared. Fifty milliliters of the prepared pitch/quinoline solution was dropped into a $500 \mathrm{ml}$ of acetone container with stirring. Since the acetone-soluble pitch was removed already, the pitch precipitated in the acetone as ultra-fine particles (UFP). Distilled water, equal to half amount of the acetone, was added into the pitch/quinoline/acetone suspension system as a flocculant. Then, the aggregated UFPs were separated by a suction filtration using a glass filter $(4 G)$. Twenty milligrams of the obtained UFP was treated with iodine at $90{ }^{\circ} \mathrm{C}$ for $1-5$ hours. The treatment was carried out through vapor phase. The iodine treated UFP was carbonized at $800{ }^{\circ} \mathrm{C}$ for 1 hour in $\mathrm{Ar}$ flow with the heating rate of $2.5^{\circ} \mathrm{C} / \mathrm{min}$. The morphology of UFP was observed with a transmission electron microscope (TEM : JEOL, JEM2000EX).

\section{Results and Discussion}

Fig.1 shows TEM photographs of obtained UFP. The obtained UFP was irregular in shape and aggregated to each other. As shown in Fig.1, the size of UFP derived from CTP was smaller than that from A240 in both pitch/quinoline ratios. Kodamas) reported that the pitch/quinoline ratio ranging from $0.005 \mathrm{~g} / \mathrm{ml}$ to $0.1 \mathrm{~g} / \mathrm{ml}$ affected little on the size of UFP derived from coal tar based mesophase pitch. However, the size of UFP obtained from a $0.02 \mathrm{~g} / \mathrm{ml}$ ratio was smaller than that from $0.1 \mathrm{~g} / \mathrm{ml}$ one for both pitches in this study. The finest UFP with about $50 \mathrm{~nm}$ in diameter was obtained from CTP in $0.02 \mathrm{~g} / \mathrm{ml}$ ratio. In the meantime, connected structure was observed in the UFP made from A240 with $0.1 \mathrm{~g} / \mathrm{ml}$ ratio. From these results, the size of UFP can be controlled by pitch/quinoline ratio and starting materials.

Iodine treatment was carried out to UFP obtained from $0.02 \mathrm{~g} / \mathrm{ml}$ of pitch/quinoline ratio. Fig. 2 indicates (a)

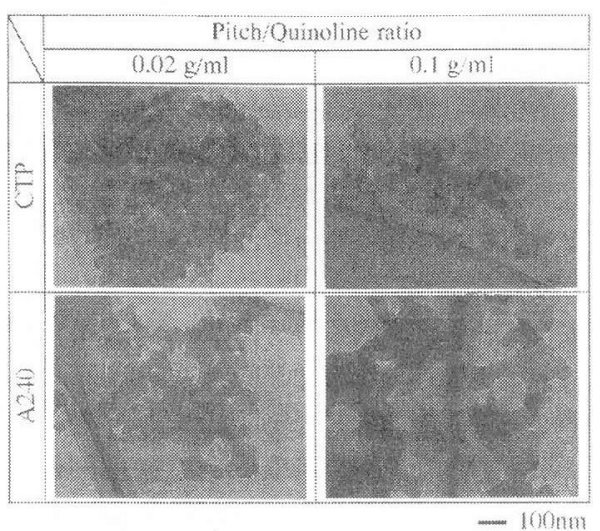

Fig.1 TEM photographs of obtained UFP.
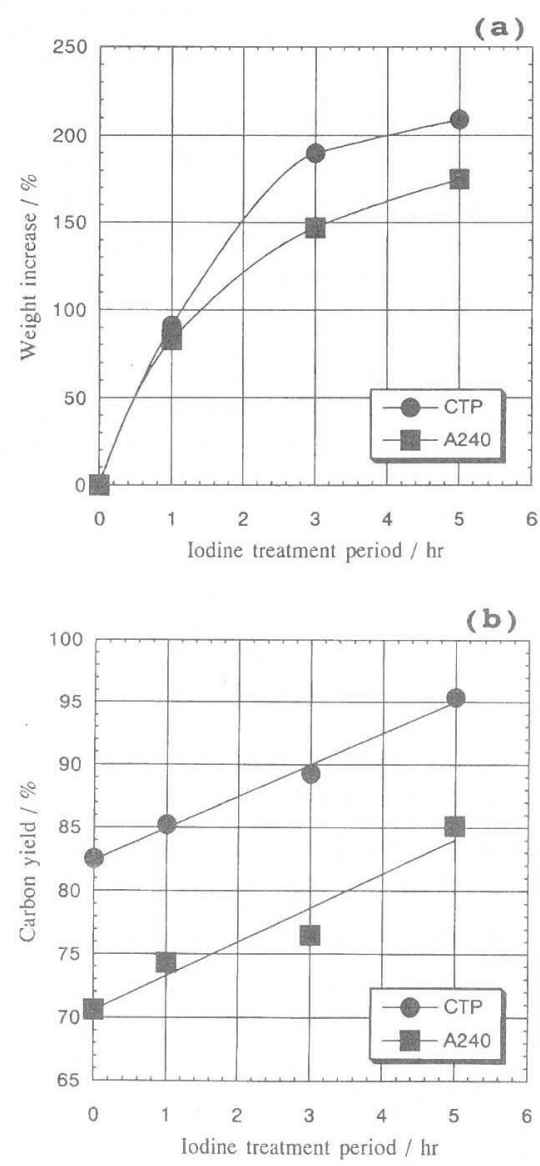

Fig.2 Effects of iodine treatment period on (a) an increase in weight of UFP and (b) carbon yield after heat treatment at $800{ }^{\circ} \mathrm{C}$.

weight increase of specimen after the iodine treatment and (b) carbon yield after heat treated at $800{ }^{\circ} \mathrm{C}$ as a 
function of the iodine treatment period. The weight increase and carbon yield in Fig. 2 were calculated based on the weight of original UFP. After the iodine treatment, the weight of specimen increased with increasing of the treatment period. Comparing with the UFP derived from A240, a greater deal of iodine was introduced into the UFP made from CTP, presumably due to different characteristics such as aromaticity between CTP and $\mathrm{A} 240$, and a $210 \%$ of weight increase was realized after 5 hours' iodine treatment. As shown in Fig.2 (b), the carbon yield increased from $83 \%$ to $95 \%$ and $70 \%$ to $85 \%$ for the CTP derived UFP and the A240 derived one, respectively. The increase of carbon yield was due to the dehydrogenative reactions which occurred between introduced iodine and components in the UFP during the heat treatment ${ }^{6)}$. The dehydrogenative reactions result in an increase in molecular weights of constituents. With a visual inspection, the outward appearance of UFP from CTP treated with iodine for 3 and 5 hours was maintained after carbonization. As for UFP from A240, the outward appearance of 3 hours' iodine treated specimen changed into spherical shape after carbonization,

(a) CTP-UFP(O.02g/ml)

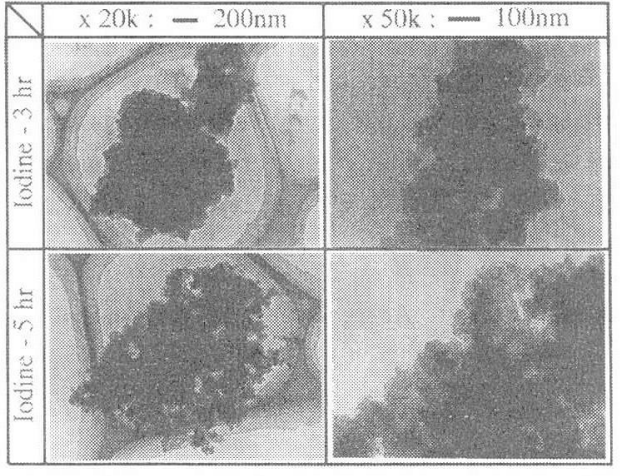

(b) A240-U1) $(0.02 \mathrm{~g} / \mathrm{ml})$

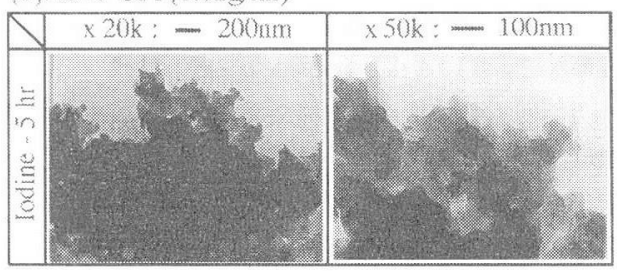

Fig.3 TEM photographs of carbonized UFP. meanwhile, the outward form of 5 hours' iodine treated specimen was maintained after carbonization.

The TEM photographs of these carbonized UFPs are presented in Fig.3. For the CTP derived UFP (a), though the UFP connected to each other, the morphology of UFP was almost maintained in 3 hours' iodine treated specimen. On the other hand, in 5 hours' iodine treated UFP, the morphology was not maintained after carbonization and was changed into husk like structure. Considering from these results, an appropriate iodine treatment condition has to carry out to maintain its morphology after carbonization for CTP derived UFP. As for the A240 derived UFP (b) treated with iodine for 5 hours, the specimen was heat treated without morphological change.

\section{Conclusions}

The authors prepared UFP from CTP and A240 pitch by anti-solvent procedure. Our conclusions are as follows. (1) The size of the obtained UFP depended upon the pitch/quinoline ratio and starting materials. The UFP with about $50 \mathrm{~nm}$ in diameter could be obtained from CTP. (2) The carbon yield of the UFP increased by the iodine treatment. (3) The UFP was able to be stabilized by the iodine treatment.

\section{Acknowledgment}

One of the authors, H.Kajiura, is indebted to the Ministry of Education, Science, Sports and Culture of Japan for financial support by Grant-in-Aid for JSPS Fellows (No.2339).

\section{References}

1) S.H.Yoon, Y.D.Park, and I.Mochida, Carbon 30, (1992) 781-786

2) M.Inagaki and M.Sakai, TANSO 1988 (No.134), 175-187

3) M.Kodama and H.Honda, Carbon 31, (1993) 839-841.

4) E.Yasuda, H.Kajiura, Y.Tanabe, A.Kaiho, and I.Shiota, Proceedings of Carbon and Carbonaceous composite materials, Czech Republic, 1995.10.10-13, in press

5) M.Kodama, Kinouzairyou 15 (No.11), (1995) 18-27.

6) H.Kajiura, E.Yasuda, and Y.Tanabe, 22nd Annual Meeting of the Carbon Society of Japan, Nagasaki, 1995.11.30-12.2, 1C13 